\title{
Drones, wind turbines, and preventing propellers from rotating in phase
}

\author{
Andrew Bell ${ }^{1}$
}

Received: 29 June 2015 / Accepted: 2 July 2015 / Published online: 15 July 2015

(C) Australian Acoustical Society 2015

In the light of recent discussion in your pages about the audibility and annoyance of wind turbines, your readers might be interested to hear of new technology being developed by NASA to reduce the sound of drones, pilotless aircraft driven by multiple motors and propellers. NASA has developed what it calls LEAP (Leading Edge Asynchronous Propeller) technology to prevent the multiple propellers on a drone from rotating in phase. By doing so, noise levels are reduced compared to the synchronous condition.

This is the same situation encountered with multiple turbines in a wind farm, where they can operate asynchronously (under most conditions) or synchronously (if the blades of one turbine become entrained with those of another, especially under steady wind conditions at night). Although wind turbines operate at a substantially lower frequency, I believe the parallels between the two configurations are striking, and it reinforces the idea set out in a recent Technical Note in your journal [1]. The note suggested that one way of reducing noise levels in a wind farm is to prevent multiple turbines from rotating in phase. This NASA work seems to support the validity and practicality of such an approach, and this letter draws it to the attention of your readers.

A description of the LEAP technology appears in an article in the 20 June issue of New Scientist [2]. In summary, LEAP has emerged from the NASA Langley Research Center and is built into the latest GL-10 drone, a prototype which carries 10 electric-driven propellers, 8 on the wings and 2 on the tail. LEAP technology uses precise digital control of the motors to ensure that they always run at slightly different speeds, meaning that the 10 sound sources remain out of synch and that there can be no constructive interference-which one would get if the propellers turned coherently.

It would be interesting if wind farm operators were to try the technology on their wind turbines and see if it led to a reduction in peak sound levels and in the number of noise complaints from people living nearby.

\section{References}

1. Bell, A.: Constructive interference of tonal infrasound from synchronised wind farm turbines: evidence and implications. Acoust. Aust. 42(3), 212-218 (2014)

2. Downloaded from http://www.newscientist.com/article/dn27696silence-of-the-drones-how-to-quiet-that-annoying-aerial-buzz. html\#.VYyl4UbD_pI. Accessed 29 Jun (2015)
Andrew Bell

andrew.bell@anu.edu.au

1 Australian National University, Canberra, ACT, Australia 